\title{
Quality of life and perceived health status in surviving adults with univentricular heart
}

\author{
Z Saliba, G Butera, D Bonnet, P Bonhoeffer, E Villain, J Kachaner, D Sidi, L Iserin
}

\begin{abstract}
Objective-To evaluate the quality of life in patients with univentricular heart and to determine the impact of sociodemographic and clinical characteristics.

Design and setting-Retrospective, cross sectional study conducted in a regional paediatric cardiology centre.

Patients-The health records of 89 survivors with univentricular heart (median age 21 years; range 17-49 years) were reviewed. Sixty seven answered the Duke questionnaire. Sociodemographic and clinical variables were similar in the responders and non-responders. The impact of sociodemographic and clinical variables on individual Duke's measures was assessed.

Results-The Duke scores of adults with univentricular heart were similar to the normal population. Cyanosis predicted a worse score for physical $(p=0.05)$ and perceived health measures $(p=0.02)$. A higher educational level predicted a better score for physical $(p=0.004)$, mental $(p=0.01)$, and general health measures $(p=0.02)$. Orthopaedic problems worsened the social score $(\mathrm{p}=0.05)$. Psychosocial problems worsened the pain score $(p=0.04)$. In comparison with the other anatomical types, mitral atresia worsened the perceived health score $(\mathrm{p}=0.02)$. Patients younger than 23 years scored better for almost all health and dysfunction measures.
\end{abstract}

Conclusions-Despite repeated interventions and other disease related everyday stresses, a selected group of adults with univentricular heart had a satisfying quality of life.

(Heart 2001;86:69-73)

Keywords: congenital heart defect; quality of life; psychosocial problems; univentricular heart

Univentricular heart is a subgroup of complex congenital heart disease in which a biventricular repair can never be achieved. While this wide spectrum of cardiac malformations accounts for less than $5 \%$ of congenital heart diseases, ${ }^{12}$ the management of these patients is difficult and has to be adapted to each individual, and most patients with univentricular heart have to undergo repeated palliative procedures during infancy. In spite of improvements in surgical techniques, mortality remains high and heart transplantation is often the ultimate procedure in adolescents and adults with this heart defect. ${ }^{2-7}$

Efforts are now being made to assess physical

Service de Cardiologie Pédiatrique and Institut de Cardiologie Congénitale des Adultes, Hôpital Necker-Enfants Malades, 149 rue de Sèvres, 75743 Paris Cedex 15, France Z Saliba

G Butera

D Bonnet

P Bonhoeffer

E Villain

J Kachaner

D Sidi

L Iserin

Correspondence to: Dr Bonnet

damien.bonnet@,

nck.ap-hop-paris.fr

Accepted 28 February 2001 health objectively and to compare the effect of different surgical procedures in patients with univentricular hearts. ${ }^{8}$ Hitherto, however, there have been few studies designed to evaluate the quality of life in this situation. An understanding by health professionals of the subjective experiences and dilemmas of such patients may improve their care as they grow up and face the challenges of an uncertain future. ${ }^{10}$ It may also be helpful in providing counselling for the parents of children with severe heart disease, especially during their adolescence and young adulthood. Finally, prenatal counselling can be expected to rely on objective data about the expected quality of life.

Measuring the quality of life is a complex task. Our aim in this study was to evaluate quality of life in adult patients with univentricular hearts using the Duke health profile.

\section{Methods}

PATIENTS

In this retrospective study, 357 patients born before 1982 (age > 18 years) with the diagnosis of "single ventricle" anomaly were examined at least once in our institution. At the time of the study, 268 of the patients were either reported to be dead or were living abroad. The health records of the remaining 89 surviving patients who were living in France were reviewed and they were all enrolled in the study. Among these 89 patients, 67 answered the Duke questionnaire (12 could not be reached by phone during the study period, six refused to participate for personal reasons, and four were unable to answer the questionnaire because of profound learning difficulties).

Table 1 Sociodemographic and medical characteristics of the 89 enrolled patients

\begin{tabular}{lrc}
\hline Sociodemographic and medical characteristics & Yes & No \\
\hline Congestive heart failure & 15 & 74 \\
Fixed pulmonary hypertension & 9 & 80 \\
Cyanosis ( $\mathrm{SaO}_{2} \leqslant 88 \%$ at rest) & 33 & 56 \\
Cardiac rhythm disturbances & 24 & 65 \\
Pacemaker & 8 & 81 \\
Interventional catheterisation & 14 & 75 \\
Postoperative complication(s) & 17 & 72 \\
Orthopaedic problems & 12 & 77 \\
Congenital extracardiac malformation(s) & 5 & 84 \\
Psychosocial problems & 6 & 83 \\
Job $\quad 27$ & 62 \\
Successful pregnancy & 2 & 47 \\
Lifestyle: With parents & 47 & \\
$\quad$ Special institution & 14 & \\
$\quad$ Independent & 28 &
\end{tabular}

$\mathrm{SaO}_{2}$, arterial oxygen saturation. 
Table 2 The 17 items of the Duke questionnaire

\begin{tabular}{|c|c|c|c|}
\hline & $\begin{array}{l}\text { Yes, describes } \\
\text { me exactly }\end{array}$ & $\begin{array}{l}\text { Somewhat } \\
\text { describes me }\end{array}$ & $\begin{array}{l}\text { No, doesn't } \\
\text { describe me } \\
\text { at all }\end{array}$ \\
\hline \multicolumn{4}{|l|}{ 1. I like who I am } \\
\hline \multicolumn{4}{|l|}{ 2. I am not an easy person to get along with } \\
\hline \multicolumn{4}{|l|}{ 3. I am basically a healthy person } \\
\hline \multicolumn{4}{|l|}{ 4. I give up too easily } \\
\hline \multicolumn{4}{|l|}{ 5. I have difficulty concentrating } \\
\hline \multicolumn{4}{|l|}{ 6. I am happy with my family relationships } \\
\hline \multicolumn{4}{|l|}{ 7. I am comfortable being around people } \\
\hline $\begin{array}{l}\text { TODAY would you have any physical trouble or } \\
\text { difficulty: }\end{array}$ & None & Some & A lot \\
\hline \multicolumn{4}{|l|}{ 8. Walking up a flight of stairs? } \\
\hline \multicolumn{4}{|l|}{ 9. Running the length of a football field? } \\
\hline $\begin{array}{l}\text { DURING THE PAST WEEK, how much trouble } \\
\text { have you had with: }\end{array}$ & None & Some & A lot \\
\hline \multicolumn{4}{|l|}{ 10. Sleeping? } \\
\hline \multicolumn{4}{|l|}{ 11. Hurting or aching in any part of your body? } \\
\hline \multicolumn{4}{|l|}{ 12. Getting tired easily? } \\
\hline \multicolumn{4}{|l|}{ 13. Feeling depressed or sad? } \\
\hline \multicolumn{4}{|l|}{ 14. Nervousness? } \\
\hline DURING THE PAST WEEK, how often did you: & None & Some & A lot \\
\hline \multicolumn{4}{|l|}{$\begin{array}{l}\text { 15. Socialise with other people (talk or visit with } \\
\text { friends or relatives)? }\end{array}$} \\
\hline \multicolumn{4}{|l|}{$\begin{array}{l}\text { 16. Take part in social, religious, or recreation } \\
\text { activities (meetings, church, movies, sports, } \\
\text { parties)? }\end{array}$} \\
\hline DURING THE PAST WEEK, how often did you: & None & 1-4 days & 5-7 days \\
\hline $\begin{array}{l}\text { 17. Stay in your home, a nursing home, or hospital } \\
\text { because of sickness, injury, or other health } \\
\text { problem? }\end{array}$ & & & \\
\hline
\end{tabular}

SOCIODEMOGRAPHIC AND MEDICAL

CHARACTERISTICS OF THE 89 ENROLLED PATIENTS

There were 42 male and 47 female patients. Their median age was 21 years (range 17-49 years) and the mean (SD) age was 22.7 (5.9) years. The morphological types of univentricular heart were as follows: 35 with tricuspid

Table 3 Sociodemographic and medical variables in the 89 enrolled patients tested by univariate analysis

Fixed pulmonary hypertension (yes or no)

Rhythm disturbances (yes or no)

Pacemaker (yes or no)

Cyanosis (yes or no)

Cardiac transplantation or awaiting for transplantation (yes or no)

Postoperative complication (yes or no)

Congenital extracardiac malformation (yes or no)

Number of surgical interventions

Number of drugs taken daily

Interventional catheterisation (yes or no)

Psychosocial problems (yes or no)

Orthopaedic problems (yes or no)

Congestive heart failure (yes or no)

Type of single ventricle $(1=$ tricuspid atresia; $2=$ double inlet heart; $3=$ mitral atresia; $4=$ others $)$

Job (yes or no)

Lifestyle (1=with parents, $2=$ special institution, $3=$ independent)

Educational level (1=low; $2=$ intermediate; $3=$ high) atresia, 24 with double inlet ventricle, 13 with mitral atresia, and 17 with other defects.

Nine patients had had no surgery. A Fontan operation or total cavopulmonary shunt had been performed in 40 patients. Thirty six had undergone a palliative shunt (aortopulmonary or cavopulmonary shunts). Four patients had undergone heart transplantation and four others were on the waiting list for a transplant at the time of the study. The average number of drugs taken daily was 2.5 per patient (range $0-5$ drugs). Other sociodemographic and medical data are summarised in table 1 .

INSTRUMENT

The Duke health profile is a 17 item generic self report instrument containing six health measures (physical, mental, social, general, perceived health, and self esteem), and four dysfunction measures (anxiety, depression, pain, and disability). ${ }^{11} \mathrm{~A}$ list of the 17 items in the Duke questionnaire is given in table 2 . Scores for multi-item measures are means of total raw item scores normalised to a scale of 0.0 to 100.0. High scores for the health items and measures indicate good health, while high scores for the dysfunction items and measures indicate poor health.

The first contact with the patient was made by telephone. At the end of the conversation, patients were informed that another copy of the questionnaire would be mailed to them. The data from both copies were analysed separately.

STATISTICAL METHODS

Data are expressed as frequency for nominal variables and as mean (SD) for continuous variables. Duke health profile scores were also expressed as a mean $z$ score $(95 \%$ confidence interval) using the nomograms published by Guillemin and colleagues. ${ }^{12}$ The temporal stability of the Duke scores during a 1-2 month interval was studied using the paired $t$ test. Univariate comparisons of Duke scores with sociodemographic and medical variables (table 3) were tested for using the unpaired $t$ test, the Mann-Whitney U test, analysis of variance, or the Kruskall-Wallis test, as appropriate. Multiple linear regression analysis was used to assess the relation between Duke scores, age, sex, and sociodemographic and medical variables when it was significant in univariate analysis. The change point test was used to determine whether there was a change in Duke scores according to age; we also sought to assess the age from which the change was greatest. ${ }^{13}$ All tests were two sided. Probability values $p<5 \%$ were considered significant.

\section{Results}

OVERALL DATA

There were no differences between phone responders and non-responders according to age, sex, and sociodemographic and medical variables. Duke scores (both health and dysfunction measures) did not differ significantly between the 67 phone responders and healthy controls. Scores expressed as mean (SD) and as $z$ scores (mean with 95\% confidence intervals) are presented in table 4 . 
Table 4 Duke scores in the 67 phone responders with z scores, compared with healthy French peers ${ }^{12}$

\begin{tabular}{llll}
\hline $\begin{array}{l}\text { Duke health } \\
\text { profile items }\end{array}$ & Mean (SD) & $\begin{array}{l}\text { Mean z score (low 95\%/ } \\
\text { high 95\% CI) }\end{array}$ & $\begin{array}{l}\text { Mean (SD), } \\
\text { healthy peers }\end{array}$ \\
\hline Physical health & $59.8(21.3)$ & $-1.02(-1.3 /-0.74)$ & $78.3(18.01)$ \\
Mental health & $68.7(21.5)$ & $-0.11(-0.35 /+0.22)$ & $71.2(22.6)$ \\
Social health & $69.6(20.7)$ & $+0.14(-0.11 /+0.4)$ & $66.8(20.1)$ \\
General health & $66.0(16.8)$ & $-0.36(-0.6 /-0.11)$ & $72.0(16.5)$ \\
Perceived health & $76.9(33)$ & $-0.07(-0.37 /+0.22)$ & $78.9(27.5)$ \\
Self esteem & $72.5(25.2)$ & $+0.05(-0.23 /+0.34)$ & $71.4(21.3)$ \\
Anxiety & $38.5(19.3)$ & $-0.43(-0.66 /-0.23)$ & $29.5(20.8)$ \\
Depression & $30.5(21.3)$ & $-0.26(-0.5 /-0.03)$ & $24.6(22.8)$ \\
Pain & $25.4(33.0)$ & $+0.2(-0.08 /+0.47)$ & $31.2(29.3)$ \\
Disability & $9.0(27.5)$ & $-0.3(-0.72 /+0.09)$ & $3.7(16.5)$ \\
\hline
\end{tabular}

CI, confidence interval.

TEMPORAL STABILITY OF THE DUKE SCORE All patients who answered by telephone received another copy by mail within six weeks after the first interview. Forty nine subjects $(67 \%)$ answered the questionnaire by mail within 8-12 weeks. The two groups (mail responders and non-responders) were similar with regard to age, sex, and sociodemographic and medical variables. No differences for any of the Duke health scores between telephone and mail answers were found.

\section{COMPARISON FOR SOCIODEMOGRAPHIC AND}

MEDICAL VARIABLES

These results are given in table 5. Cyanotic patients scored worse for physical and perceived health measures. However, mental and social scores were not affected by cyanosis. The presence of orthopaedic problems worsened the social score. Patients with a higher educational level scored better for mental, physical, and general health measures. Patients with mitral atresia scored worse for perceived health measure compared with other anatomical types of univentricular heart. Psychosocial problems (parent-child conflict) worsened the pain score. Finally, younger patients scored better for almost all health and dysfunction measures.

HEALTH SCORES AND AGE

The change point test was used to determine whether there was a change in Duke score distribution according to age. The change point was found to be 23 years. We then compared Duke scores in patients younger than and older than 23 years. We found that health and dysfunction scores where significantly better in the younger subjects (table 6).
Table 6 Comparison between patients older and younger than 23 years in the 67 phone responder patients

\begin{tabular}{llll}
\hline & $\begin{array}{l}\leqslant 23 \text { years } \\
(n=46)\end{array}$ & $\begin{array}{l}>23 \text { years } \\
(n=21)\end{array}$ & p Value \\
\hline Physical health & $64(20)$ & $51(22)$ & 0.02 \\
Mental health & $72(21)$ & $62(22)$ & 0.05 \\
General health & $69(15)$ & $59(18)$ & 0.02 \\
Perceived health & $85(30)$ & $60(34)$ & 0.003 \\
Anxiety & $35(19)$ & $44(18)$ & 0.08 \\
Pain & $18(29)$ & $41(37)$ & 0.03 \\
\hline
\end{tabular}

Values are mean (SD) Duke score.

\section{Discussion}

Over the past two decades, mortality in univentricular heart has been reduced and many patients now reach adulthoodunfortunately at the expense of repeated hospital admissions and surgical procedures. The psychological impact of these repeated procedures is probably more important in adolescents. In addition, patients are usually aware of the potential reduction in their life expectancy and physical capabilities, as well as of the need for repeated risky procedures.

There have been several studies on the intellectual, social, and emotional development and adjustment of children and adolescents with congenital heart disease, and on mother-child relations and parental stress. ${ }^{14-19}$ However, studies on the quality of life in such patients have reached ambiguous conclusions. Several investigators have reported negative psychosocial outcomes in these patients - for example, diminished self esteem, anxiety, depression, and poor emotional or social adjustment. ${ }^{20-23}$ Conversely, more optimistic outcomes and a normal quality of life in selected types of congenital heart disease have been observed in other studies. ${ }^{142425}$

The clinical applicability, validity, and especially the simplicity of the Duke health profile has made this tool attractive for measuring the quality of life in adults. In addition, it has been adapted and translated into the French language. ${ }^{12}$ Using this questionnaire, we showed that the quality of life in adults with a univentricular heart did not differ from that in a comparable population of healthy adults. These patients probably developed coping mechanisms, easing the psychological stress and thus improving the majority of the scores in the Duke profile. We speculate that they orient themselves towards a different set of values in everyday life. Disabilities may be accepted and personal expectations recalibrated. ${ }^{26}$

The temporal stability of the Duke questionnaire was confirmed in our study, as it has been

Table 5 Multiple linear regression analysis assessing relations between different Duke score items and sociodemographic and medical variables in the 67 phone responder patients

\begin{tabular}{|c|c|c|c|c|c|c|c|c|c|c|c|c|c|c|}
\hline & \multicolumn{2}{|c|}{ Physical health } & \multicolumn{2}{|c|}{ Mental health } & \multicolumn{2}{|c|}{ Social health } & \multicolumn{2}{|c|}{ General health } & \multicolumn{2}{|c|}{ Perceived health } & \multicolumn{2}{|c|}{ Anxiety } & \multicolumn{2}{|l|}{ Pain } \\
\hline & $C$ & $p$ & $C$ & $p$ & $C$ & $p$ & $C$ & $p$ & $C$ & $p$ & $C$ & $p$ & $C$ & $p$ \\
\hline Age & -1.3 & 0.002 & -0.97 & 0.02 & -1.18 & 0.01 & -1.16 & 0.001 & -2.2 & 0.0005 & +0.7 & 0.08 & +2.3 & 0.006 \\
\hline Cyanosis & -9.5 & 0.05 & - & - & - & - & - & - & -1.6 & 0.02 & - & - & - & - \\
\hline Educational level & +11 & 0.004 & +9.2 & 0.01 & - & - & +7.7 & 0.02 & - & - & - & - & - & - \\
\hline Orthopaedic problems & - & - & - & - & -12.4 & 0.05 & - & - & - & - & - & - & - & - \\
\hline Psychosocial problems & - & - & - & - & - & - & - & - & - & - & - & - & +27 & 0.04 \\
\hline \multirow{3}{*}{$\begin{array}{l}\text { Anatomical type } \\
(\mathrm{MA} v \text { other UVH })\end{array}$} & & & & & & & & & & & & & & \\
\hline & - & - & - & - & - & - & - & - & -8.7 & 0.02 & - & - & - & - \\
\hline & 0.25 & & 0.2 & & 0.2 & & 0.3 & & 0.3 & & 0.1 & & 0.2 & \\
\hline
\end{tabular}

C, coefficient; MA, mitral atresia; UVH, univentricular hearts. 
in chronic congestive heart failure and chronic pulmonary obstructive disease. ${ }^{27}{ }^{28}$ However, its reliability in our study population may be questioned. In particular, is it logically possible to conclude that the physical health status of adults with univentricular hearts does not differ from that of their normal peers? In reviewing the questions in the Duke profile separately, it is worth noting that the answer to the question, "Would you have any physical trouble or difficulty walking up a flight of stairs?" was "some" in about $50 \%$ of the patients. On the other hand, the score on pain items was good in the majority of cases, making the total score of "physical health" comparable to that in normal adults.

Social isolation and mental health impairment have been reported in children and adolescents with congenital heart disease..$^{21} 29$ These may occur as a result of physical incapacity, restricted leisure time activities, and parental overprotectiveness. Such patients have a reduced level of cognitive development, related at least in part to a decreased opportunity for interaction between the child and the environment. ${ }^{20}$ In our study, social and mental scores were normal. Here again, the mental score was automatically overestimated by the exclusion of the four patients with severe learning difficulties already mentioned.

Early studies indicated a significant incidence of psychiatric disturbances in children and adults after cardiac surgery, ${ }^{30}{ }^{31}$ the possible aetiology of these including organic causes such as cerebral anoxia or microembolism. Another factor that might be implicated is the sensory and sleep deprivation that occurs in the intensive care unit. ${ }^{20}$

In studies of intellectual function, children with congenital heart disease-and specifically those with cyanosis - scored lower than normal children. Later in life a better estimate of ultimate intellectual capacity may be obtained from adaptive and social behaviour. ${ }^{32}$ In our study, and regardless of the age of the patients, neither mental nor social scores were modified by cyanosis. Only physical and perceived health scores were lower in cyanotic patients.

A univentricular heart impairs physical capacity. Thus affected patients are at risk of personal and social disability. ${ }^{29}{ }^{33}$ Unexpectedly, the self esteem score was normal in our study population.

A worsening of the majority of Duke scores with age may be related in part to uncertainties over the course and outcome of the disease, which lead to an increased sense of vulnerability in these patients.

\section{CONCLUSIONS}

We aimed to evaluate the quality of life in surviving adults with one of the most severe forms of congenital heart disease. Despite repeated hospital admissions, surgical interventions, and other disease related everyday stresses, a selected group of these patients may survive for a relatively long time with a good quality of life. Our ultimate goal is to learn more about the needs of these survivors in an effort to increase our understanding of ways to prevent or alleviate some of the problems that accompany this type of congenital heart disease.

We gratefully acknowledge the physicians and paramedical staff who assisted us in gathering data. ZS is a recipient of the 1998 SESERAC grant (Société d'Etudes et de Soins pour les Enfants atteints de Rhumatisme Articulaire aigu et de Cardiopathies).

1 Kirklin JW, Barratt-Boyes BG. Cardiac surgery, 2nd ed. New York: Churchill Livingstone, 1993:1549.

2 Steinberg EH, Dantzker DR. Single ventricle with severe pulmonary hypertension: natural survival into the third decade of life. Am Heart $\mathcal{f}$ 1993;125:1451-3.

3 Moodie DS, Ritter DG, Tajik AJ, et al. Long-term follow-up in the unoperated univentricular heart. Am $\mathcal{F}$ Cardiol 1984; 53:1124-8.

4 Goldberg HL, Sniderman K, Devereux RB, et al. Prolonged survival (62 years) with single ventricle. Am f Cardiol 1983; 52:214-15.

5 Patel MM, Overy DC, Kozonis MC, et al. Long-term survival in tricuspid atresia. $\mathcal{F}$ Am Coll Cardiol 1987;9:338-

6 Cohen D. Surgical management of congenital heart disease in the 1990s. Am F Dis Child 1992;146:1447-52.

7 Sagar KB, Mauck HP. Univentricular heart in adults: report of nine cases with review of the literature. Am Heart $\mathcal{F}$ 1985;110:1059-62.

8 Knott-Craig CJ, Fryar-Dragg T, Overholt ED, et al. Modified hemi-Fontan operation: an alternative definitive palliation for high-risk patients. Ann Thorac Surg 1995;60: 554-7.

9 Bonnet D, Acar P, Aggoun Y, et al. Les dérivations cavo-pulmonaires partielles peuvent-eles Mal Coeur Vaiss 1998;91:569-73.

10 Tong EM, Sparacino PS, Messias DK, et al. Growing up with congenital heart disease: the dilemmas of adolescents and young adults. Cardiol Young 1998;8:303-9.

11 Parkerson GR, Broadhead WE, Tse CK. The Duke health profile. A 17-item measure of health and dysfunction. Med profile. A 17-1tem meas

12 Guillemin F, Paul-Dauphin A, Virion JM, et al. Le Profil de anté de DUKE: un instrument générique de mesure de qualité de vie liée à la santé. Sante Publique 1997;9:35-44.

13 Siegel S, Castellan JN. Nonparametric statistics for behavioural ciences. New York: McGraw-Hill, 1998.

14 DeMaso DR, Beardslee WR, Silbert AR, et al. Psychological functioning in children with cyanotic heart defects. $\mathcal{F}$ Dev Behav Pediatr 1990;11:289-94.

15 Utens EM, Verhulst FC, Meijboom FJ, et al. Behavioural and emotional problems in children and adolescents with congenital heart disease. Psychol Med 1993;23:415-24.

16 Goldberg S, Washington J, Morris P, et al. Early diagnosed chronic illness and mother-child relationships in the first two years. Can $\mathcal{F}$ Psychiatry 1990;35:726-33.

17 Goldberg S, Simmons RJ, Newman J, et al. Congenital heart disease, parental stress, and infant-mother relationships. $\mathcal{F}$ Pediatr 1991;119:661-6.

18 Tong EM, Sparacino PS. Special management issues for Tong EM, Sparacino PS. Special management issues for Crit Care Nurs Clin North Am 1994;6:199-214.

19 Uzark K. Counseling adolescents with congenital heart disease. $\mathcal{F}$ Cardiovasc Nurs 1992;6:65-73.

20 Linde LM. Psychiatric aspects of congenital heart disease. Psychiatr Clin North Am 1982;5:399-406.

21 Donovan E. The pediatric cardiologist and adolescents with congenital heart disease. Int $\mathcal{F}$ Cardiol 1985;9:493-5.

22 Kramer HH, Awiszus D, Sterzel U, et al. Development of personality and intelligence in children with congenital heart disease. F Child Psychol Psychiatry 1989;30:299-308.

23 Garson SL, Baer PE. Psychological aspects of heart disease in childhood. In: Garson A, Bricker JT, McNamara DG, eds. The science and practice of pediatric cardiology, Philadelphia: Lea and Febiger, 1989:2519-27.

24 Gersony WM, Hayes CJ, Driscoll DJ, et al. Second natural history study of congenital heart defects. Quality of life of patients with aortic stenosis, pulmonary stenosis, or patients with aortic stenosis, pulmonary stenosis,
ventricular septal defect. Circulation 1993;87:152-65.

25 O’Dougherty M, Wright FS, Garmezy N, et al. Later competence and adaptation in infants who survive severe heart defects. Child Dev 1983;54:1129-42.

26 Saigal S, Feeny D, Rosenbaum P, et al. Self-perceived health status and health-related quality of life of extremely ow-birth-weight infants at adolescence. $\mathscr{F} A M A$ 1996;276: 453-9.

27 Briancon S, Alla F, Mejat E, et al. Mesure de l'incapacité fonctionnelle et le qualité de vie dans l'insuffisance cardiaque. Adaptation transculturelle et validation des questionnaires de Goldman, du Minnesota, et de Duke. Arch Mal Coeur Vaiss 1997;90:1577-85.

28 Hoang Thi TH, Guillemin F, Cornette A, et al. Healthrelated quality of life in long-term oxygen-treated chronic obstructive pulmonary disease patients. Lung 1997;175: 63-71.

29 Spurkland I, Bjornstad PG, Lindberg H, et al. Mental health and psychosocial functioning in adolescents with congenital heart disease. A comparison between adolescents born with severe heart defect and atrial septal defect. Acta Paediatr 1993;82:71-6.

30 Haka-Ikse K, Blackwood MJ, Steward DJ. Psychomotor development of infants and children after profound 
hypothermia during surgery for congenital heart disease. Dev Med Child Neurol 1978;20:62-70.

31 Rimon R, Lehtonen J, Scheinin TM. Psychiatic disturbances after cardiovascular surgery. Acta Psychiatr Scand Suppl 1968;203:125-30.
32 Linde LM, Rasof B, Dunn OJ. Mental development in congenital heart disease. F Pediatr 1967;71:198-203.

33 Casey FA, Craig BG, Mulholland HC. Quality of life in surgically palliated complex congenital heart disease. Arch Dis Child 1994;70:382-6.

\section{IMAGES IN CARDIOLOGY}

\section{Endomyocardial fibrosis mimicking a dilated cardiomyopathy in a child}

A 15 year old girl with a history of asthma had, at the age of 9 years, a diagnosis of idiopathic dilated cardiomyopathy (IDCM). On admission the patient was asymptomatic, with no medical treatment. Peripheral blood eosinophilia was absent. Resting ECG revealed a sinus rhythm with a left bundle branch block. Two dimensional (cross sectional) echocardiography showed a globus and dilated left ventricle with mildly reduced left ventricular (LV) function (LV ejection fraction $48 \%$ ). No echogenic apical mass or endocardial thickening of one or both ventricles were visible.

Cardiac catheterisation showed a moderate increase of LV end diastolic pressure with a

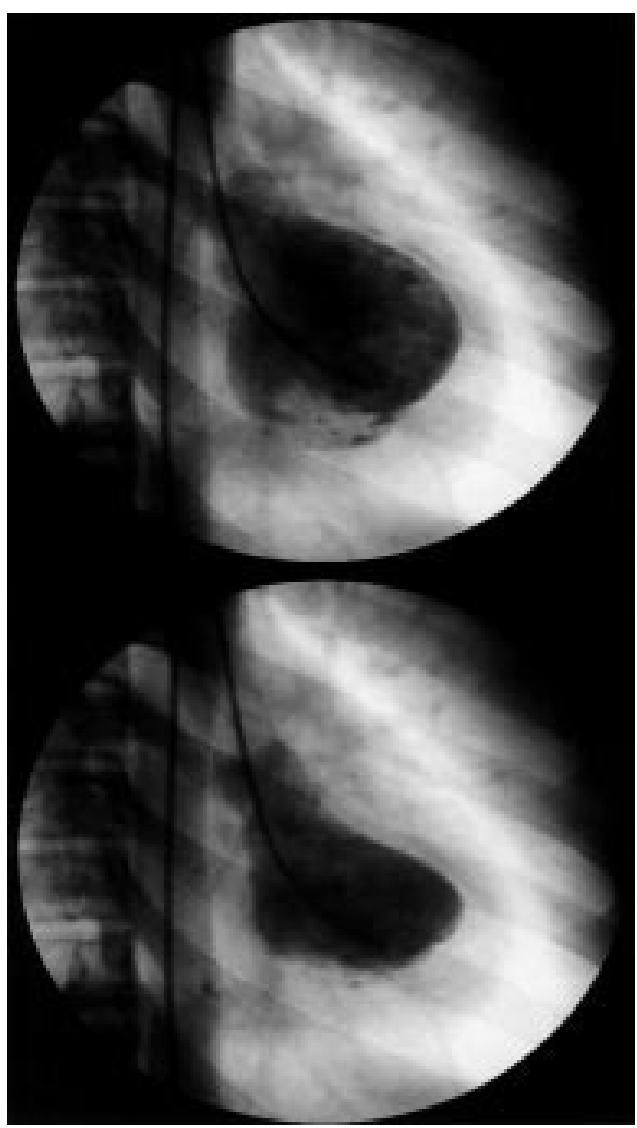

dip-plateau pattern. Unpredictably, LV angiography revealed a localised filling defect of the posterior wall with complete obliteration of the LV apex (right anterior oblique view, top $=$ diastole, bottom $=$ systole $)$, without mitral valve regurgitation. Right heart catheterisation showed a mild increase of systolic and mean pulmonary pressures and, at angiography, the ventricle had normal dimensions and function. Biventricular endomyocardial biopsy was performed and, at histology, a discrepancy between left and right ventricular features was evident. Right ventricular histology was compatible with the diagnosis of IDCM. Conversely, histology of the left ventricle showed a notably thickened endocardium $(1.2 \mathrm{~mm})$, with a three zonal layering appearance (dense fibrous (A), loose fibrous (B), and granulating tissue layers (C)) suggestive of endomyocardial fibrosis. Surgical treatment was not considered, as the patient was asymptomatic and no mitral regurgitation was present.

This case should alert physicians to be cautious when a child presents with a suspected IDCM and to take into consideration unusual disorders, such as endomyocardial fibrosis.

CRISTINA CHIMENTI MAURIZIO PIERONI ANDREA FRUSTACI biocard@rm.unicatt.it

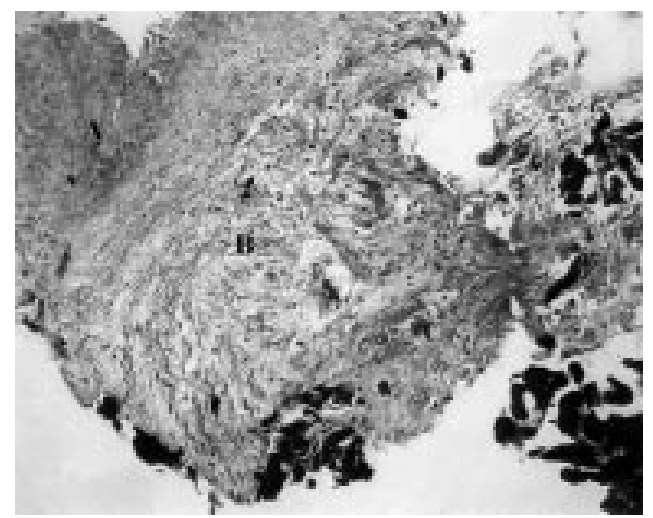

